\title{
Comparative Analysis of Chilling Response in Cucumber Through Plastidic and Nuclear Genetic Effects Component Analysis
}

\author{
Vanessa S. Gordon ${ }^{1,3}$ and Jack E. Staub ${ }^{2}$ \\ Vegetable Crops Research Unit, U.S. Department of Agriculture, Agricultural Research Service, \\ Department of Horticulture, University of Wisconsin, 1575 Linden Drive, Madison WI 53706
}

\begin{abstract}
AdDitional INDEX wORDs. chilling injury, environmental stress, abiotic tolerance, plastid, SNP, breeding, cucurbits, Cucumis sativus

ABstract. Chilling damage can cause major reductions in cucumber (Cucumis sativus L.) yield. Cucumber plants can withstand a chilling event (i.e., tolerance and susceptibility), in which response is dictated primarily by maternally inherited plastid genomes or by the biparental contribution of a nuclear factor. To examine the modes of inheritance, exact reciprocal backcross cucumber populations $\left(\mathrm{BC}_{1}{ }_{5}\right)$, were created by crossing 'Chipper' (chilling-tolerant plastid, susceptible nucleus) and line North Carolina State University (NCSU) M29 (chilling-susceptible plastid, susceptible nucleus). These progeny and their parents were subjected to chilling stress $\left[5.5 \mathrm{~h}\right.$ at $4^{\circ} \mathrm{C}$ in $270 \mu \mathrm{mol} \cdot \mathrm{m}^{-2} \cdot \mathrm{s}^{-1}$ photosynthetic photon flux $(P P F)$ cool white lighting] at the first true-leaf stage. The chilling response of individuals possessing either NCSU M29 or 'Chipper' cytoplasm in any generational comparison was not significantly different $(P>0.05)$ from that of the maternal plastid source (susceptible or tolerant). Moreover, lines within a plastid type did not differ significantly $(P>0.05)$ in chilling response despite unequal nuclear contributions demonstrating the absence of nuclear additive or dosage effects originating in 'Chipper' or NCSU M29. Additionally, line NC-76, previously identified as a nuclear source of chilling tolerance, performed intermediate to 'Chipper' and NCSU M29 in chilling response under these stress conditions. The $\mathrm{F}_{1}$ progeny derived from crossing both $\mathrm{BC}_{5}$ plastidic response types (susceptible and tolerant) with NC-76 (paternal parent) performed comparable to their plastid donors and were significantly different $(P<\mathbf{0 . 0 0 0 1})$ from one another despite their heterozygous nuclear nature resulting from the contribution of the nuclear chilling-tolerant factor contributed by NC-76. The response of tolerant and susceptible $\mathrm{BC}_{5}$ lines (i.e., 'Chipper' plastid in the NCSU M29 background and NCSU M29 plastid in 'Chipper' background, respectively) was reversible by crossing $\mathrm{BC}$ progeny with an alternate chilling-response plastid type. It is concluded that under these chilling conditions, plastid effects determine tolerance or susceptibility in the cucumber germplasms examined.
\end{abstract}

Associating stress physiology with a specific genotype that can be manipulated in an applied breeding program is frequently a complex task (Kreps et al., 2002), because related biochemical pathways are often shared in the form of "cotolerances" (Choi et al., 2002; Foolad et al., 1999; Iturriaga et al., 2006; Kant et al., 2008; Komori and Imaseki, 2005; Sabehat et al., 1998; Takahashi et al., 2005). However, despite such complications, the study and classification of genetic factors conferring tolerance to abiotic stressors such as chilling temperatures are an important agricultural goal of many plant improvement programs.

Chilling response can have a direct effect on yield, particularly in crops grown outside their recommended climatic zones (Lynch, 1990). For example, cucumber is a tropical plant often sown in temperate regions where temperatures often fluctuate dramatically in the early spring as seedlings germinate and emerge. Cucumber is very sensitive to chilling, and recovery period from such challenges is relatively long (Chung et al., 2003; Staub and Bacher, 1997). Symptoms associated with chilling injury $(\mathrm{CI})$ in cucumber seedlings include poor

Received for publication 12 Jan. 2011. Accepted for publication 25 Apr. 2011. ${ }^{1}$ Present address: Abbott \& Cobb Inc., 11460 Fortune Circle, West Palm Beach, FL 33414.

${ }^{2}$ Present address: USDA, ARS Forage and Range Research Laboratory, $696 \mathrm{~N}$. 1100 E., Logan, UT 84322.

${ }^{3}$ Corresponding author. E-mail: vanessa_gordon@abbottcobb.com. germination and emergence, seedling death, and yellow or necrotic tissue. Mature fruit may experience surface pitting, tissue deterioration, yellowing, water soaking, and increased levels of both water loss and greater susceptibility to pathogens after a chilling challenge. Maternal (Chung et al., 2003) and nuclear (Kozik and Wehner, 2008) inheritance patterns have been proposed as genetic explanations of response to chilling temperatures (less than $12^{\circ} \mathrm{C}$ ) in cucumber.

Complex nuclear-plastid intercommunications are present within plant cells (Goldschmidt-Clermont, 1998; Gray and Greenberg, 1992; Mayfield, 1990; Rodermel, 2001; Susek and Chory, 1992), and as such, it is likely that both entities have the capacity for affecting some component of chilling response. It remains unclear in many plant species to what degree each interacts with the other or, more importantly, where the abiotic stress response originates for particular developmental stages and what environmental conditions elicit adverse effects. The maternally inherited chilling response in cucumber documented by Chung et al. (2003) was followed by a report by Kozik and Wehner (2008) suggesting that there is also a nuclear factor that influences chilling response. Not only did the temperature and duration of chilling differ between the studies of Chung et al. (2003) and Kozik and Wehner (2008), but also the genetic background of the accessions evaluated varied [i.e., 'Chipper' (tolerant) and Gy14 (susceptible) in the former and NC-76 (tolerant), 'Chipper' (slightly tolerant), and Gy14 (susceptible) in the latter]. Moreover, neither of these studies 
considered the consequence of additive or dosage effects contributed by cytoplasmic or nuclear factors on chilling response.

Chung et al. (2007) identified putative plastidic single nucleotide polymorphisms (SNPs) (bp locations: 4813, 56561, and 126349) associated with CI in cucumber (susceptibility and tolerance). However, the role of the SNPs as genetic factors controlling specific biochemical pathways has not been defined. Given the differing modes of inheritance proposed for CI (Chung et al., 2003; Kozik and Wehner, 2008) and the lack of understanding of potential cytoplasmic and nuclear interactions during chilling in cucumber (Chung et al., 2007), a study was designed to: 1) elucidate the expression of the maternally inherited chilling response using exact reciprocal backcross generations created from crosses between 'Chipper' and NCSU M29 (susceptible); 2) determine whether the effects of maternal factors for chilling response are influenced by nuclear genes for chilling tolerance using $F_{1}$ progeny that combined both the plastidic components as well as the nuclear source of chilling tolerance from NC-76 (Kozik and Wehner, 2008), and; 3) determine the effects of "re-introgression" of a plastid response type into its original nuclear background. Not only will this study provide a better understanding of the genetics of $\mathrm{CI}$, but it will allow for the development of chilling tolerant germplasm for cucumber improvement.

\section{Materials and Methods}

Germplasm. Three cucumber lines were chosen for experimentation based on both their previously determined response to chilling temperatures (Kozik and Wehner, 2008; Smeets and Wehner, 1997; Wehner, 1982) and their potential for development of commercially acceptable germplasm. Although NCSU M29 (P2) is chilling-susceptible, both 'Chipper' (P1) and NC76 (P3) are chilling-tolerant based on these previous studies. These lines were obtained from the U.S. Department of Agriculture-Agricultural Research Service cucumber breeding program in Madison, WI ('Chipper' and NCSU M29, hereafter designated as $\mathrm{CH}$ and $\mathrm{M} 29$, respectively) and the NCSU cucurbit breeding program in Raleigh, NC (NC-76).

EXPERIMENTAL PROGENY. An initial exact reciprocal cross was made between two (one each) $\mathrm{CH}$ (P1) and M29 (P2) plants by hand pollination in a greenhouse at the University of Wisconsin (UW), Madison. These and their derived advanced backcross progenies were used in three experiments to examine various hypotheses concerning the effects on chilling response of different plastid types. Strategic comparisons were made because highly inbred recurrent parental plants were selfpollinated each generation, providing pollen for each successive generation of crossing.

Random $\mathrm{F}_{1}$ progeny were successively backcrossed to their paternal genetic donor [i.e., $\mathrm{BC}_{1}-\mathrm{BC}_{5}$, Expt. 1 (Fig. 1A)]. Advanced reciprocal $\mathrm{BC}_{5}$ progeny, resulting from the initial crosses between $\mathrm{CH}$ and M29 [CH $\times$ M29 $\left(\mathrm{CBC}_{5}\right.$, synonym P4) and $\mathrm{M} 29 \times \mathrm{CH}\left(\mathrm{MBC}_{5}\right.$, synonym P5)], were crossed to $\mathrm{NC}-76$ (P3) to create $F_{1}$ progeny [Expt. 2 (Fig. 1B)]. In this case, $F_{1}$ progeny possessing both nuclear and plastidic chilling response factors were created using $\mathrm{CBC}_{5}[\mathrm{P} 4$ (line possessing the tolerant $\mathrm{CH}$ plastid with theoretically greater than $98 \%$ of M29 nuclear background)] and $\mathrm{MBC}_{5}$ [P5 (line possessing the susceptible M29 plastid with theoretically greater than $98 \%$ of $\mathrm{CH}$ nuclear background)] as maternal parents in matings with $\mathrm{NC}-76$ as the pollen donor. In addition, $\mathrm{CBC}_{5}$ and $\mathrm{MBC}_{5}$ were crossed to M29 and $\mathrm{CH}$ (maternal parents), respectively, to create re-introgression $F_{1}$ progeny (i.e., introduction of the original tolerant or susceptible plastid type into advanced backcross progeny possessing the original nuclear material) [Expt. 3 (Fig. 1C)]. This allowed for a single mating to provide progeny for a direct comparison (e.g., $\mathrm{CBC}_{5} \times \mathrm{M} 29$ versus $\left.\mathrm{M} 29 \times \mathrm{CBC}_{5}\right)$ of chilling response with plastidic factors as the sole variable.

Pre-chilling growing conditions. Parents and experimental progeny, from all generations for the three experimental setups, were simultaneously and completely randomized, assigned numbers, and sown in peat pots $\left(185 \mathrm{~cm}^{3}\right)$ containing a sterilized 1 sand:1 peatmoss mixture. Each parental line/ hybrid/generation was represented by six individuals in each of four replications (i.e., 24 individuals). The seeds were germinated in the greenhouse at $29{ }^{\circ} \mathrm{C}$ (daylight conditions) $/ 24{ }^{\circ} \mathrm{C}$ (dark conditions) with an applied bottom heat of $35^{\circ} \mathrm{C}$ to the germination flats. Seedlings, in the cotyledon stage, were then transported into a controlled environmental chamber in the UW-Madison Biotron (Madison, WI). Seedlings were grown at $22{ }^{\circ} \mathrm{C}$ (light) $/ 18{ }^{\circ} \mathrm{C}$ (dark) under a 9-h photoperiod at a light level of $600 \mu \mathrm{mol} \cdot \mathrm{m}^{-2} \cdot \mathrm{s}^{-1} \mathrm{PPF}$ (0800 to $1700 \mathrm{HR}$ ) supplied by cool-white fluorescent and incandescent lamps according to Chung et al. (2003). Relative humidity (RH) was held at 60\%. Seedlings were watered, at soil level, twice per day to saturation and fertilized with $20 \mathrm{~N}-8.8 \mathrm{P}-16.6 \mathrm{~K}$ fertilizer (Peter's; Scotts, Marysville, $\mathrm{OH}$ ) once per week.

Chilling protocol And Damage Ratings. Seedlings with first-true leaves emerged and fully opened with no remaining adaxial leaf curl were subjected to a chilling treatment of $5.5 \mathrm{~h}$ (0800 to $1330 \mathrm{HR}$ ) at $4{ }^{\circ} \mathrm{C}$ (immediate and constant) where the light level was $270 \mu \mathrm{mol} \cdot \mathrm{m}^{-2} \cdot \mathrm{s}^{-1} P P F$ supplied by only cool white lamps according to Chung et al. (2003). This provided a uniform physiological age for chilling damage assessment.

During chilling treatment, $\mathrm{RH}$ was $52 \%$. Before chilling, seedlings were watered at the soil level only to the extent of eliminating dryness and were provided the standard watering on conclusion of the chilling protocol. After chilling, plants were returned to pretreatment conditions, and leaf damage was quantified by visual rating $5 \mathrm{~d}$ after the chilling treatment.

Visual ratings on a total of 288 individuals [136 tolerant plastid-type (CH maternal source) and 152 susceptible plastidtype (M29 maternal source)] were made using a previously determined scale ranging from 0 to 9 , in which $0=$ no damage, 1 to $2=$ trace injury, 3 to $4=$ slight injury, 5 to $6=$ moderate damage, 7 to $8=$ advanced damage, and $9=$ plant death (Smeets and Wehner, 1997).

DAta ANALYSIS. Visual rating data were subjected to analysis of variance (ANOVA) using the PROC GLM procedure in SAS (Version 9; SAS Institute, Cary, NC). Generation least squares means, SD, and their attending 95\% confidence limits (CLs) were calculated for each experiment (three). Strategically designed parent and progeny performance comparisons were made using a $t$ test analysis $(P<0.01)$.

Notation of PLASTIDIC TYPES. Parents and cross-progeny were given the plastid chilling sensitivity designation of $s$ for susceptible and $t$ for tolerant, in which sensitivities are presented as prefixes in describing generation plastid status and original maternal source (e.g., $t \mathrm{CF}_{1}$ signifying $\mathrm{CH}$-tolerant plastid type in the $\mathrm{F}_{1}$ generation). Additionally, the annotation, - and --, is used here to designate plastid and nuclear constitution of a genotype, respectively. For example, backcross $\mathrm{CBC}_{5}$ progeny 

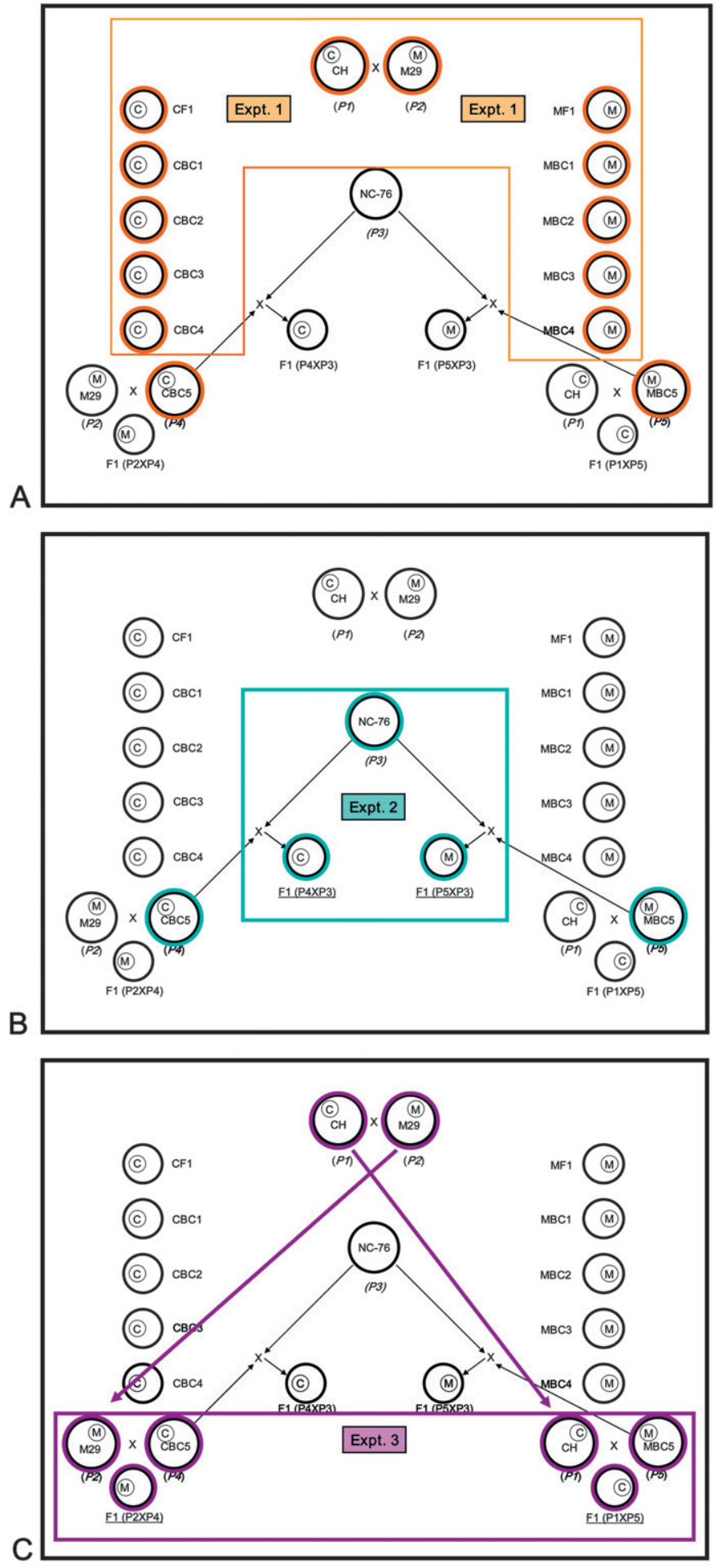

Fig. 1. A diagrammatic representation of three cucumber chilling experiments conducted under controlled conditions [5.5 h $(0800$ to $1330 \mathrm{HR})$ at $4{ }^{\circ} \mathrm{C}$ (immediate and constant) where the light level was $270 \mu \mathrm{mol} \cdot \mathrm{m}^{-2} \cdot \mathrm{s}^{-1}$ photosynthetic photon flux $(P P F)$ supplied by only cool white lamps]. Expt. 1 (A) tested responses for exact reciprocal backcross populations $\left(\mathrm{BC}_{1}-{ }_{5}\right)$ created from cucumber lines 'Chipper' (CH) and NCSU M29 (M29). Expt. 2 (B) evaluated chilling response of combined plastid and nuclear tolerant progeny resulting from a combination of both nuclear and plastid sources of cucumber chilling tolerance (NC-76 and $\mathrm{CH}$, respectively). Expt. 3 (C) tested the response of $\mathrm{F}_{1}$ "re-introgression" progeny, derived in two cytoplasmic backgrounds ( $\mathrm{CH}$ and M29), to directly assess hypothesized tolerant versus susceptible plastidic genotypes.

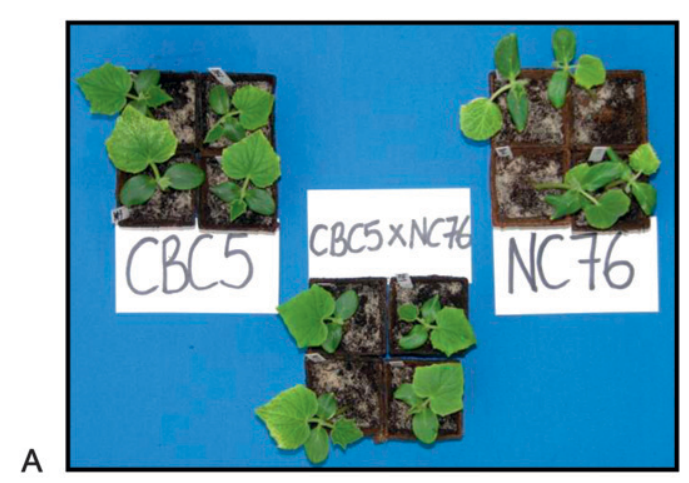

B

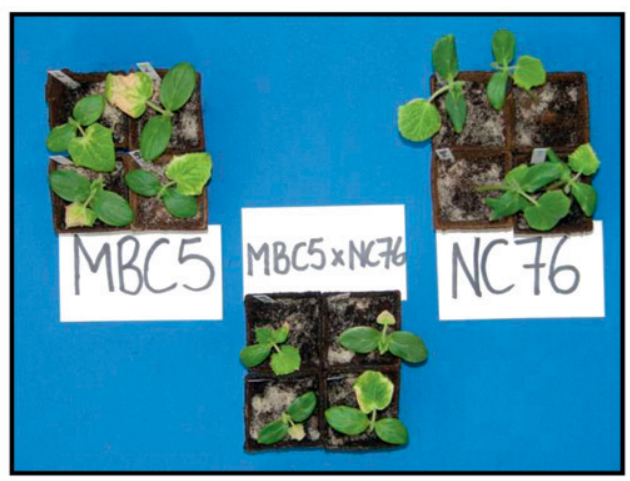

Fig. 2. Chilling responses of cucumber parental lines and $F_{1}$ progeny possessing both nuclear and plastidic chilling tolerance, in which $\mathrm{NC}-76, \mathrm{Ch}=$ nuclear tolerance, and 'Chipper' and NCSU M29 (M29) possessing plastidic tolerance $(t)$ and susceptibility $(s)$, respectively; and $\mathrm{F}_{1}$ progeny are tolerant $\left(\mathbf{A} ; \mathrm{CBC}_{5} \times\right.$ NC-76) and susceptible $\left(\mathbf{B} ; \mathrm{MBC}_{5} \times \mathrm{NC}-76\right)$. Plants were chilled for $5.5 \mathrm{~h}$ (0800 to $1330 \mathrm{HR}$ ) at $4{ }^{\circ} \mathrm{C}$ (immediate and constant) where the light level was $270 \mu \mathrm{mol} \cdot \mathrm{m}^{-2} \cdot \mathrm{s}^{-1}$ photosynthetic photon flux $(P P F)$ supplied by only cool white lamps.

(putative chilling-tolerant) are designated as $t / c h c h$, whereas $\mathrm{MBC}_{5}$ progeny (putative chilling-susceptible) are given the notation of s/chch. Neither $\mathrm{CH}$ nor M29 is known to have tolerant nuclear genes, and, thus, their nuclear contribution is annotated as chch. In contrast, the chilling-tolerant nuclear genome of NC-76 is denoted as ChCh and Chch when in the homozygous and heterozygous state, respectively. Because the notation $s$ defines a susceptible plastid type, the mating, $\mathrm{CBC}_{5} \times \mathrm{NC}-76$, creates an $\mathrm{F}_{1}$ with a plastid and nuclear notation, $t / C h c h$, whereas progeny of a $\mathrm{MBC}_{5} \times \mathrm{NC}-76$ mating are designated $s /$ Chch.

\section{Results}

The lack of adequate seed in progeny generations precluded multiple chilling evaluations and, thus, a single completely randomized experiment without blocking was designed to include a large number of plants (experimental unit). This design evaluated a larger sampling per entry (average sample per entry $=23$ ) than previously described in cucumber chilling experiments using the same conditions as those described here [average sample size per entry $=$ six individuals (Smeets and Wehner, 1997) and 17 individuals (Chung et al., 2003)] as well as providing an opportunity for data collection across all entries simultaneously. This methodology also provided a precise assessment of damage ratings (i.e., increased discrimination of damage rating classes) while minimizing the effects of environment (i.e., a single post-chilling treatment recovery site). 
Additionally, all parents and cross-progeny were simultaneously compared under identical conditions in all specific cross-comparisons across all experimental categories.

EXPT. 1: EXACT ReCiprocal popUlations. Expt. 1 tested whether backcross progeny (i.e., $\mathrm{BC}_{1}$ to $\mathrm{BC}_{5}$ ) exhibited chilling tolerance equivalent to their respective maternal parent and whether chilling response during backcrossing was altered by the introgression of nuclear factors resident in the susceptible and tolerant parental lines (Fig. 1A). The mean chilling ratings of tolerant and susceptible parental plastid sources $\mathrm{CH}(\mathrm{P} 1)$ and M29 (P2) were 2.5 (1.0 sD, 95\% CL = 2.0 to 3.1) and $5.4(1.7 \mathrm{sD}$, $95 \% \mathrm{CL}=4.8$ to 6.0 ), respectively (Table 1). Although reciprocal cross-progenies of each generation [i.e., $\mathrm{F}_{1}(\mathrm{P} 1 \times \mathrm{P} 2$ and $\mathrm{P} 2 \times \mathrm{P} 1)$ and $\mathrm{BC}_{1-5}\left(\mathrm{BC}_{1} \mathrm{P} 2-\mathrm{BC}_{5} \mathrm{P} 2\right.$ and $\left.\left.\mathrm{BC}_{1} \mathrm{P} 1-\mathrm{BC}_{5} \mathrm{P} 1\right)\right]$ differed $(P<0.0001)$, progeny performance within any one population was not different. Thus, although no differences were detected between chilling responses of cross-progeny plants containing the same maternally inherited plastid type, the response of parental $\mathrm{CH}$ and M29 lines differed from progeny $\left(\mathrm{F}_{1}\right.$ and $\left.\mathrm{BC}_{1-5}\right)$ in which they were the paternal recurrent nuclear donor. This indicated that their respective additive nuclear contributions did not influence chilling response.

Analysis of maternal effects indicated that the performance of $\mathrm{CH}$-derived backcross progeny (136) did not differ from their plastid donor parent $(P=0.44)$ (Table 1). Likewise, the chilling response of M29-derived progeny (152) did not differ from M29 $[P=0.76$ (susceptible plastid)]. However, $\mathrm{CH}$ - and M29-derived progeny in alternate cytoplasmic backgrounds [i.e., $\mathrm{CH}$ versus $\mathrm{F}_{1}$ and $\mathrm{BC}_{1-5}$ (having the M29-type plastid type)] and [M29 versus $\mathrm{F}_{1}$ and $\mathrm{BC}_{1-5}$ (having the $\mathrm{CH}$-type plastid type $)$ differed $(P<0.0001)$ in their chilling response. Thus, the chilling response observed in specific cross-progeny (CH- or M29-plastid background) persisted across generations $\left(\mathrm{F}_{1}\right.$ to $\left.\mathrm{BC}_{5}\right)$ despite an increasing nuclear contribution $\left[(1 / 2)^{n}\right]$

Table 1. Mean, SD, and $95 \%$ confidence limits of chilling $\left(4{ }^{\circ} \mathrm{C}\right.$ for $5.5 \mathrm{~h}$ at $\left.270 \mu \mathrm{mol} \cdot \mathrm{m}^{-2} \cdot \mathrm{s}^{-1} P P F\right)$ injury ratings in parental cucumber lines ('Chipper' and NCSU M29) and their reciprocal $\mathrm{F}_{1}, \mathrm{BC}_{1}, \mathrm{BC}_{2}, \mathrm{BC}_{3}, \mathrm{BC}_{4}$, and $\mathrm{BC}_{5}$ progeny (Expt. 1). ${ }^{\mathrm{z}}$

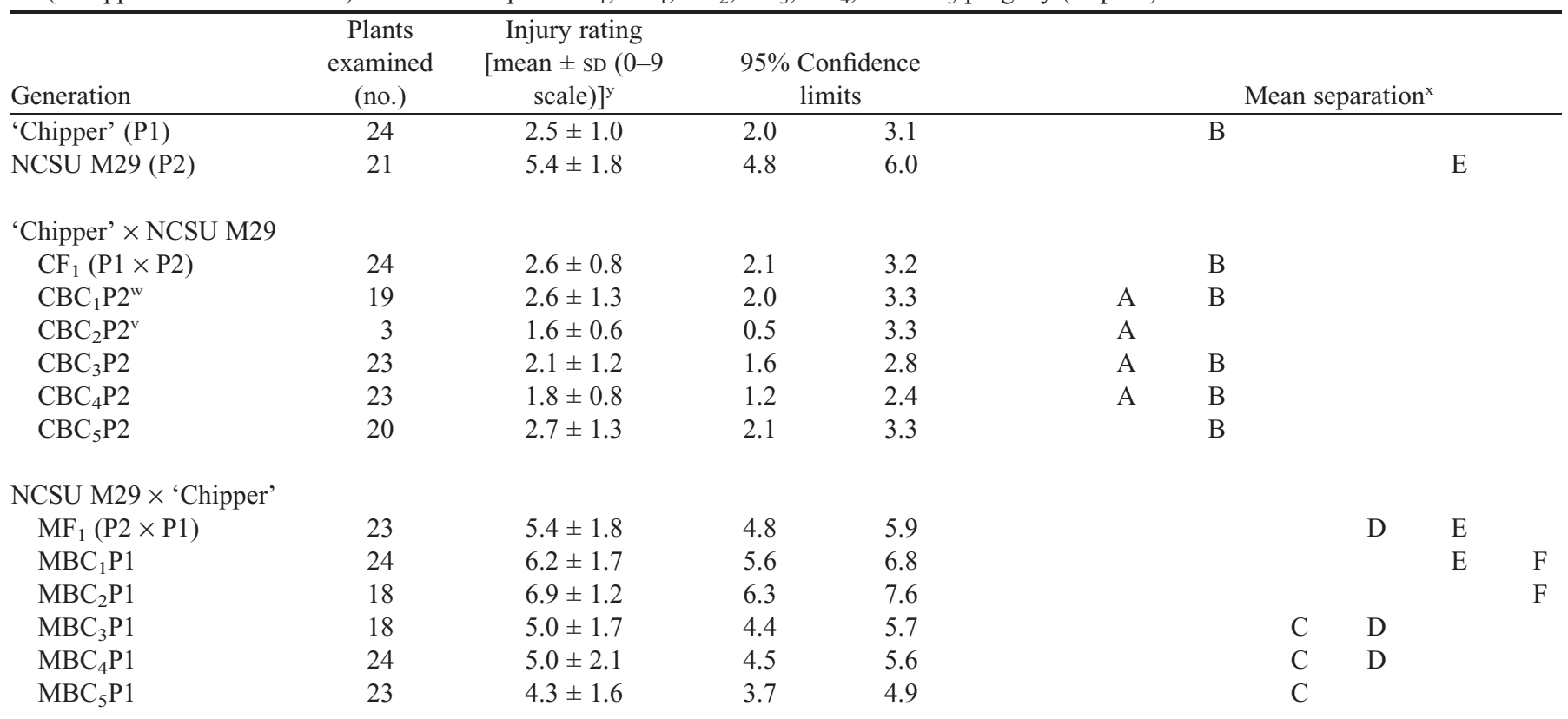

Reciprocal mean comparisons

$\mathrm{F}_{1} \quad \mathrm{P} 1 \times \mathrm{P} 2(2.6)$ versus $\mathrm{P} 2 \times \mathrm{P} 1(5.3)$

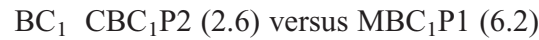

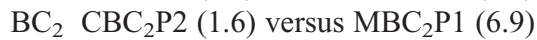

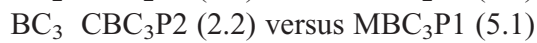

$\mathrm{BC}_{4} \quad \mathrm{CBC}_{4} \mathrm{P} 2(1.8)$ versus $\mathrm{MBC}_{4} \mathrm{P} 1(5.0)$

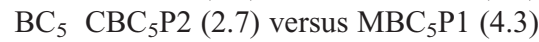

Reciprocal difference $P$ values

$\begin{array}{lr}\text { 'Chipper' versus } \mathrm{F}_{1} \text { through } \mathrm{BC}_{5} \text { (C-type) plastid lines } & 0.4377 \\ \text { NCSU M29 versus } \mathrm{F}_{1} \text { through } \mathrm{BC}_{5} \text { (M-type) plastid lines } & 0.7588 \\ \text { 'Chipper' versus } \mathrm{F}_{1} \text { through } \mathrm{BC}_{5} \text { (M-type) plastid lines } & <0.0001 \\ \text { NCSU M29 versus } \mathrm{F}_{1} \text { through } \mathrm{BC} 5 \text { (C-type) plastid lines } & <0.0001\end{array}$

'Chipper' versus $\mathrm{F}_{1}$ through $\mathrm{BC}_{5}$ (C-type) plastid lines $\quad 0.4377$

'Chipper' versus $\mathrm{F}_{1}$ through $\mathrm{BC}_{5}$ (M-type) plastid lines

NCSU M29 versus $\mathrm{F}_{1}$ through BC5 (C-type) plastid lines $\quad<0.0001$

\footnotetext{
${ }^{\mathrm{z}}$ Generational data may be repeated among tables as chilling protocol was conducted simultaneously across all germplasm in Expts. 1, 2, and 3. yPlants subjected to $4{ }^{\circ} \mathrm{C}$ for $5.5 \mathrm{~h}$ at $270 \mu \mathrm{mol} \cdot \mathrm{m}^{-2} \cdot \mathrm{s}^{-1} P P F$, in which $0=$ no damage, 1 to $2=$ trace damage, 3 to $4=$ slight damage, 5 to $6=$ moderate damage, 7 to $8=$ advanced damage, and $9=$ dead [according to Chung et al. (2003) and Smeets and Wehner (1997)]. Data are means of ratings at first true-leaf in four replications.

${ }^{x}$ Least significant difference grouping at $P<0.05$.

${ }^{\text {w}}$ Cucumber line names initiated with letter indicating maternal plastid contribution, in which C $=$ 'Chipper' (tolerant) plastid and M = NCSU M29 (susceptible) plastid with $\mathrm{CBC}_{n}$ indicating an advanced backcross [recurrent parent $=$ NCSU M29 (P2)] derived from an original cross of 'Chipper' $\times$ NCSU M29 $(\mathrm{P} 1 \times \mathrm{P} 2)$ or $\mathrm{MBC}_{n}$ indicating an advanced backcross [recurrent parent $=$ 'Chipper' $(\mathrm{P} 1)$ ] derived from the reciprocal of that cross.

${ }^{\mathrm{V}}$ Reduced entries as a result of seed germination failures.

$P P F=$ photosynthetic photon flux.
} 
of the paternal recurrent donor with each backcross and an equivalent decrease in nuclear contribution of the maternal (non-recurrent) parent.

EXPT. 2: CUMUlative Plastid AND NUClEAR CHILling RESPONSE Expt. 2 tested whether the chilling response of $\mathrm{F}_{1}$ generated plastid types ( $s=$ susceptible and $t=$ tolerant $)$ differed in the presence of the nuclear NC-76 Ch chilling tolerance gene (Fig. 1B). Although the mean chilling ratings of tolerant $(\mathrm{CH})$ and susceptible (M29) lines were $2.5(1.0 \mathrm{SD}, 95 \% \mathrm{CL}=2.0$ to $3.1)$ and $5.3(1.7 \mathrm{sD}, 95 \% \mathrm{CL}=4.8$ to 6.0$)$, respectively, the mean chilling response rating of the tolerant line NC-76 [P3 (nuclear source)] was 3.7 (1.1 SD, 95\% CL=3.1 to 4.4) (Table 2; Fig. 2).

The $\mathrm{F}_{1}$ progeny derived from crossing both $\mathrm{BC}_{5}$ plastidic response types (susceptible and tolerant) with NC-76 (paternal tolerant parent) performed similarly to their plastid donors and were significantly $(P<0.0001)$ different from one another despite the heterozygous nuclear nature resulting from the contribution of the nuclear tolerant factor present in NC-76 (Table 2). The mean chilling response ratings of $\mathrm{CBC}_{5}$ and $\mathrm{MBC}_{5}$ backcross progeny were $2.7(1.3 \mathrm{SD}, 95 \% \mathrm{CL}=2.1$ to
3.3) and $4.3(1.6 \mathrm{SD}, 95 \% \mathrm{CL}=3.7$ to 4.9$)$, respectively. The mean chilling response rating of $\mathrm{CF}_{1}$ progeny $\left[t \mathrm{CF}_{1}(\mathrm{P} 4 \times \mathrm{P} 3)\right]$, possessing the tolerant plastid in an $\approx 50 \% \mathrm{M} 29(\mathrm{P} 2): 50 \% \mathrm{NC}$ 76 (P3) nuclear background, was $2.2(0.6 \mathrm{sD}, 95 \% \mathrm{CL}=1.6$ to 2.8). In contrast, $\mathrm{MF}_{1}$ progeny $\left[s \mathrm{MF}_{1}(\mathrm{P} 5 \times \mathrm{P} 3)\right]$, with a susceptible plastid in an $\approx 50 \% \mathrm{CH}(\mathrm{P} 1): 50 \%$ NC-76 (P3) nuclear background, responded negatively to chilling, yielding a mean rating of 5.5 (1.9 SD, 95\% CL $=4.9$ to 5.9$)$.

Line NC-76 demonstrated an intermediate chilling response when compared with $\mathrm{CH}$ and M29 and the reciprocal progeny populations of Expt. 1 ( $P<0.0001$ for all comparisons) (Table 2; Fig. 2). Comparative analyses of $\mathrm{CH}(\mathrm{P} 1)$ and $\mathrm{NC}-76(\mathrm{P} 3)$ to their $t \mathrm{CF}_{1}$ progeny revealed differences between $\mathrm{NC}-76$ and $t \mathrm{CF}_{1}(P=0.0004)$, but not between $\mathrm{CH}$ and $t \mathrm{CF}_{1}(P=0.42)$ in chilling response. Although the chilling response of M29 did not differ from $s \mathrm{MF}_{1}(P=0.75)$, the response of $s \mathrm{MF}_{1}$ differed from NC-76 $(P<0.0001)$. Likewise, chilling response comparisons between the two plastidic types ( $s$ and $t$ ) of contrasting $\mathrm{F}_{1}$ progeny (i.e., $t \mathrm{CF}_{1}$ and $\left.s \mathrm{MF}_{1}\right)$ were predictably different $(P<$ $0.0001)$. Thus, the chilling response of $F_{1}$ progeny heterozygous for the nuclear chilling resistance factor contributed from

Table 2. Mean, SD, and $95 \%$ confidence limits of chilling $\left(4^{\circ} \mathrm{C}\right.$ for $5.5 \mathrm{~h}$ at $\left.270 \mu \mathrm{mol} \cdot \mathrm{m}^{-2} \cdot \mathrm{s}^{-1} P P F\right)$ injury ratings in parental cucumber lines ('Chipper', NCSU M29, and NC76) and their derived $\mathrm{F}_{1}$ progeny created by advanced backcross and parental matings $\left(\mathrm{BC}_{5} \times \mathrm{NC} \mathrm{N6}\right)\left(\right.$ Expt. $\left.^{2}\right){ }^{\mathrm{z}}$

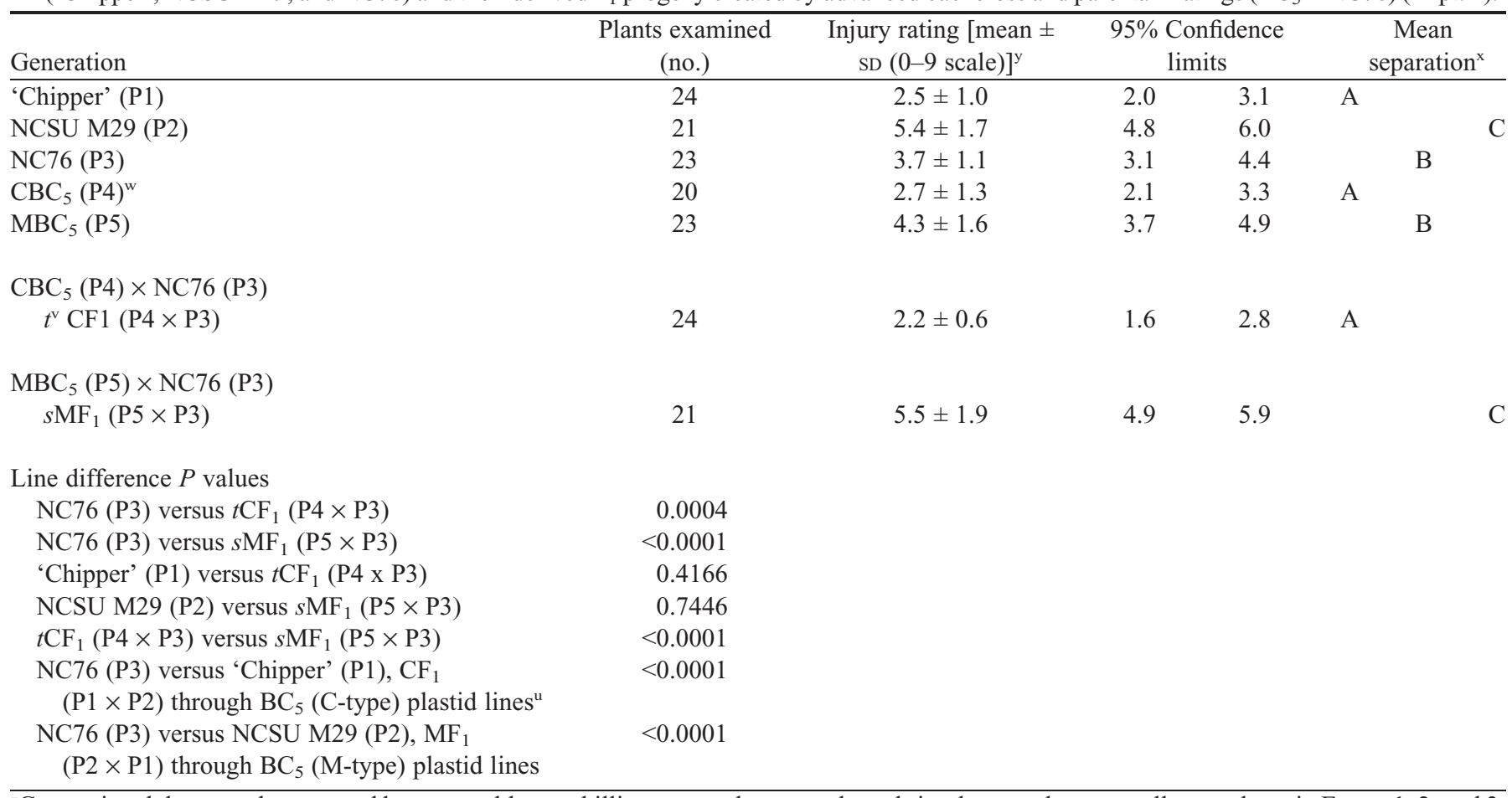

${ }^{\mathrm{z}}$ Generational data may be repeated between tables as chilling protocol was conducted simultaneously across all germplasm in Expts. 1, 2, and 3. yPlants subjected to $4{ }^{\circ} \mathrm{C}$ for $5.5 \mathrm{~h}$ at $270 \mu \mathrm{mol} \cdot \mathrm{m}^{-2} \cdot \mathrm{s}^{-1} P P F$, in which $0=$ no damage, 1 to $2=$ trace damage, 3 to $4=$ slight damage, 5 to $6=$ moderate damage, 7 to $8=$ advanced damage, and $9=$ dead [according to Chung et al. (2003) and Smeets and Wehner (1997)]. Data are means of ratings at first true-leaf in four replications.

${ }^{x}$ Least significant difference grouping at $P<0.05$.

${ }^{\mathrm{w}} \mathrm{Cucumber}$ line names initiated with letter indicating maternal plastid contribution, specifically, $\mathrm{C}=$ 'Chipper' (tolerant) plastid and $\mathrm{M}=\mathrm{NCSU}$ M29 (susceptible) plastid, with $\mathrm{CBC}_{n}$ indicating an advanced backcross [recurrent parent $=$ NCSU M29 (P2)] derived from an original cross of 'Chipper' $\times$ NCSU M29 (P1 x P2) or MBC $_{n}$ indicating an advanced backcross [recurrent parent $=$ 'Chipper' (P1)] derived from the reciprocal of that cross.

"Designation indicating $\mathrm{F}_{1}$ progeny possessing combined putative plastid and nuclear chilling factors, in which " $s$ " and " $t$ " are susceptible and tolerant plastid contributions, respectively.

uSee lines from Table 1.

$P P F=$ photosynthetic photon flux. 
NC-76 was similar to their maternal $t \mathrm{CH}$ and $s \mathrm{M} 29$ parent lines (Table 2). In contrast, the response of $F_{1}$ progeny derived from intercrosses between tolerant and susceptible parents differed despite being heterozygous $(\mathrm{Ch} / \mathrm{ch})$ for the NC-76 dominant tolerant nuclear chilling allele.

EXPT. 3: RE-INTROGRESSION CROSSES. Expt. 3 tested whether the chilling response of advanced backcross progeny having unique chilling plastid types [i.e., $t \mathrm{CBC}_{5}(\mathrm{CH}$ plastid with theoretically greater than $98 \%$ of M29 nuclear background) and $s \mathrm{MBC}_{5}$ (M29 plastid with theoretically greater than $98 \%$ of $\mathrm{CH}$ nuclear background)] is affected by plastid exchange (reintrogression) (Fig. 1C). This was accomplished by crossing $\mathrm{CBC}_{5}$ and $\mathrm{MBC}_{5}$ (paternal parents) to $\mathrm{M} 29(s)$ and $\mathrm{CH}(t)$, respectively, to produce re-introgression $\mathrm{F}_{1}$ progeny. Because neither $\mathrm{CH}$ nor M29 carries the dominant chilling tolerant nuclear gene $(C h)$ resident in NC-76, the progeny comparisons here did not consider the effect of $\mathrm{Ch}$. The mean chilling response ratings for these parental lines and backcross progeny were reported previously [Expt. 3 (Table 3)].

The mean chilling response rating of re-introgression $F_{1}$ progeny possessing $\mathrm{CH}$-tolerant cytoplasm $\left(\mathrm{CH} \times \mathrm{MBC}_{5}\right)$ was $2.8(1.0 \mathrm{SD}, 95 \% \mathrm{CL}=2.2$ to 3.3 ) (Table 3 ). In contrast, the mean rating of its counterpart re-introgression $\mathrm{F}_{1}$ progeny containing M29-susceptible cytoplasm was 4.9 (1.6 SD, 95\% $\mathrm{CL}=4.3$ to 5.5 ). The chilling response of parental lines used to derive each of the re-introgression progeny differed $(P<$ 0.0001 ) from each other (e.g., P1 versus P5 and P2 versus $\mathrm{P} 4)$. In contrast, the chilling response of re-introgression $\mathrm{CHF}_{1}$ and $\mathrm{M}_{2} 9 \mathrm{~F}_{1}$ progeny did not differ from their maternal sources [i.e., CH (P1) and M29 (P2), respectively]. Thus, re-introduction (or re-introgression) of the original plastid type (i.e., the $s$ and $t$ types of M29 and $\mathrm{CH}$, respectively) as examined in reintrogression $F_{1}$ progeny restores the chilling response to that equal to parental $\mathrm{CH}$ and M29 cultigens.

\section{Discussion}

Abiotic stresses such as chilling temperatures often occur in unpredictable patterns, making it in many cases nearly impossible to apply substantial preventative management practices for crop protection. Thus, the use of germplasm that is resistant or tolerant to abiotic stress has become an attractive managerial tool for minimizing profit loss. However, breeding for such stress resistance is often complex, long-term, and labor-intensive. In cucumber, the nuclear and maternal factors that condition chilling response are manifested under differing environmental conditions (Chung et al., 2003; Kozik and Wehner, 2008). As previously reported, chilling response of cucumber seedlings was assessed in controlled environments under different conditions, and, thus, inter-experimental comparisons are difficult. The influences of maternal and nuclear factors were examined here under uniform experimental conditions of Chung et al. (2003) to provide the first report of their respective roles in chilling response at the seedling stage.

Injury to cucumber after a chilling challenge can vary depending on chilling environment and as such is an important

Table 3. Mean, SD, and $95 \%$ confidence limits of chilling injury $\left(4^{\circ} \mathrm{C}\right.$ for $5.5 \mathrm{~h}$ at $\left.270 \mu \mathrm{mol} \cdot \mathrm{m}^{-2} \cdot \mathrm{s}^{-1} P P F\right)$ in parental cucumber lines ('Chipper' and NCSU M29) and re-introgression lines (Expt. 3). ${ }^{\mathrm{z}}$

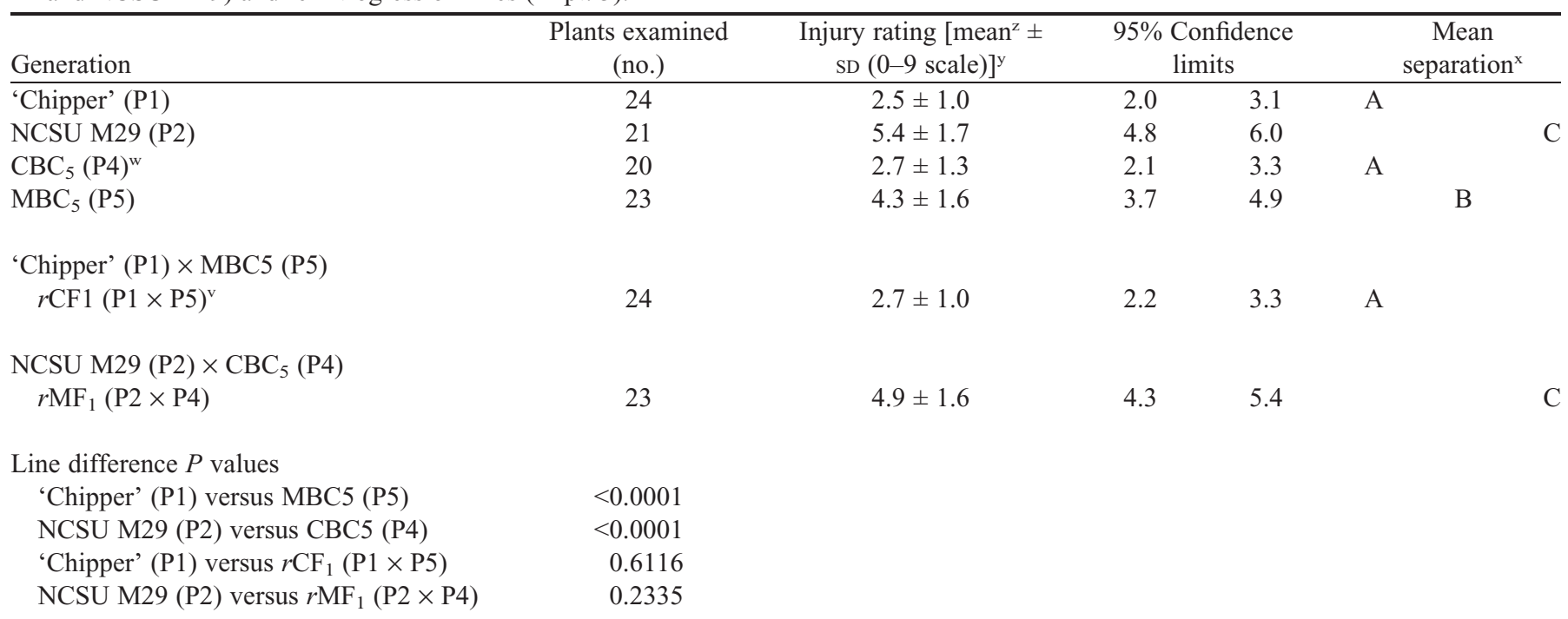

\footnotetext{
${ }^{\mathrm{z}}$ Generational data may be repeated among tables as chilling protocol was conducted simultaneously across all germplasm in Expts. 1, 2, and 3. yPlants subjected to $4{ }^{\circ} \mathrm{C}$ for $5.5 \mathrm{~h}$ at $270 \mu \mathrm{mol} \cdot \mathrm{m}^{-2} \cdot \mathrm{s}^{-1} P P F$, in which $0=$ no damage, 1 to $2=$ trace damage, 3 to $4=$ slight damage, 5 to $6=$ moderate damage, 7 to $8=$ advanced damage, and $9=$ dead [according to Chung et al. (2003) and Smeets and Wehner (1997)]. Data are means of ratings at first true-leaf in four replications.

${ }^{x}$ Least significant difference grouping at $P<0.05$.

${ }^{\text {w} C u c u m b e r ~ l i n e ~ n a m e s ~ i n i t i a t e d ~ w i t h ~ l e t t e r ~ i n d i c a t i n g ~ m a t e r n a l ~ p l a s t i d ~ c o n t r i b u t i o n, ~ i n ~ w h i c h ~} \mathrm{C}=$ 'Chipper' (tolerant) plastid and M $=\mathrm{NSCU}$ M29 (susceptible) plastid; with $\mathrm{CBC}_{5}$ indicating an advanced backcross [recurrent parent $=\mathrm{M} 29(\mathrm{P} 2)$ ] derived from an original cross of 'Chipper' $\times$ M29 $(\mathrm{P} 1 \times \mathrm{P} 2)$.

$v$ " $r$ " indicates the re-introgression of a plastid source into its original nuclear background, in which the resulting $\mathrm{F}_{1}$ progeny display the chilling phenotype of the maternal parental line.

$P P F=$ photosynthetic photon flux.
} 
consideration for the interpretation of results between experiments (Staub and Wehner, 1996). The chilling response of $\mathrm{CH}$ and M29 was originally evaluated by Smeets and Wehner (1997), who stated that genetic variation for chilling response in cucumber could be quantified under specific test conditions (i.e., $270 \mu \mathrm{mol} \cdot \mathrm{m}^{-2} \cdot \mathrm{s}^{-1} P P F$ at $4{ }^{\circ} \mathrm{C}$ for $7 \mathrm{~h}$ ). Chung et al. (2003) subsequently used a chilling duration of $5.5 \mathrm{~h}$ at $4{ }^{\circ} \mathrm{C}$ to identify the maternal factors associated with CI using the same rating system as that of Smeets and Wehner (1997). Smeets and Wehner (1997) found $\mathrm{CH}$ to be chilling-tolerant (average damage rating $=5.7$ ) and M29 susceptible (average damage rating $=7.6)$. The average chilling damage rating of $\mathrm{CH}$ differed between Smeets and Wehner (1997) and Chung et al. (2003) (mean = 2.0)]. Additionally, line M29 was evaluated by Smeets and Wehner [1997 (mean = 7.6)], but not by Chung et al. (2003). However, Smeets and Wehner (1997) found the relative CI of line Gy14 (mean $=7.7)$ to be comparable to M29. The mean chilling response of line Gy14 as estimated by Chung et al. (2003) was 6.1. Although common cultigens in each of these studies were found to perform similarly in response to chilling stress, mean damage ratings were, on average, slightly less in Chung et al. (2003). Likewise, because the conditions in our study are those set forth by Chung et al. (2003), the mean damage ratings of $\mathrm{CH}$ (2.5) and M29 (5.4) as examined here more closely correspond with the results of that study than those reported in Smeets and Wehner (1997).

Multiple genetic factors that control response to abiotic stress can add to the complexity of the interpretation of challenges such as low temperatures. Recently, Kozik and Wehner (2008) evaluated chilling in cucumber by altering experimental conditions from that of Chung et al. (2003) and Smeets and Wehner (1997) and characterized a nuclear component $(C h)$ controlling chilling response resident in NC-76. Although maintaining chilling temperature and duration as defined by Smeets and Wehner (1997), Kozik and Wehner (2008) increased the light intensity from 270 to 500 $\mu \mathrm{mol} \cdot \mathrm{m}^{-2} \cdot \mathrm{s}^{-1} P P F$ and assessed damage $14 \mathrm{~d}$ post-treatment instead of $5 \mathrm{~d}$ as was the case in both earlier studies. Under this modified chilling treatment, parental lines and cross-progeny were classified as resistant (average rating $=0$ to 2 ), moderately resistant (average rating $=3$ to 6 ), and susceptible (average rating $=7$ to 9 ) such that $\mathrm{CH}$, which was previously classified as resistant (5.7) by Chung et al. (2003), was designated as susceptible (numerical damage ratings not reported). Likewise, although line M29 (not tested by Chung et al., 2003) would be classified as susceptible by Kozik and Wehner (2008) and Smeets and Wehner (1997) if damage ratings were averaged over those experiments (mean =7.6), NC-76, homozygous $(\mathrm{ChCh})$, is classified highly resistant to chilling stress. Although no distinct numerical damage rating was applied to NC-76, data taken collectively (i.e., same visual rating scale) from the studies of Chung et al. (2003), Kozik and Wehner (2008), and Smeets and Wehner (1997) suggest that the numerical chilling damage rating attribution of highly resistant NC-76 should range between 0 to 1 and 0 to 2 , respectively.

Chilling damage rating differences among inbred lines (i.e., $\mathrm{CH}$ and M29) across experiments (Chung et al., 2003; Kozik and Wehner, 2008; Smeets and Wehner, 1997) indicate that chilling damage is environmentally dependent. These historic controlled environment outcomes suggest that the assessment of plant reaction to chilling temperature is dependent on testing location (i.e., field versus controlled environment), methodol- ogy (i.e., duration and intensity of stress), and quantification (i.e., visual assessment of stress damage). Furthermore, it is likely that any differences observed in chilling response between these historic experiments and those reported here are the result of dissimilarities in test methodology rather than chilling damage quantification, because all experiments used the visual damage rating standards set forth in Smeets and Wehner (1997).

Assessing chilling response differences is critical for deployment of novel germplasm, especially if genetic control originates from two sources (nuclear and cytoplasmic) such as cucumber. For instance, Kozik and Wehner (2008) found $\mathrm{CH}$ and Gy14 seedlings to be equally susceptible to chilling $\left(4^{\circ} \mathrm{C} / 7\right.$ $\left.\mathrm{h} / 500 \mu \mathrm{mol} \cdot \mathrm{m}^{-2} \cdot \mathrm{s}^{-1} \mathrm{PPF}\right)$ as the susceptible M29 and identified a nuclear component to chilling challenge whose effect was deemed to be greater than the plastid influence. However, in the studies reported here, chilling response data from exact reciprocal populations designed to assess the role of both plastid and nuclear factors indicated that such populations did not differ from that of their plastid parental contributors (Tables 1 and 2), supporting the results of Chung et al. (2003). Moreover, these response types (susceptible and tolerant) persisted and remained constant in backcross generations in which increasing dosages of paternal nuclear alleles were introduced into progeny. The chilling damage recorded in reciprocal crossprogeny examined here supports the observations of susceptible nuclear genotypes types made by Kozik and Wehner (2008) because the chilling response detected between backcross generations possessing varying dosages of $\mathrm{CH}$ and M29 nuclear DNA did not differ.

Multiple biochemical pathways are associated with the repair of $\mathrm{CI}$, which affect the genetic design of improved ideotypes (Kudoh and Sonoike, 2002). The experimental differences (i.e., chilling duration and light intensity) between Kozik and Wehner (2008) and Chung et al. (2003)/Smeets and Wehner (1997) could elicit genotype-dependent physiological responses (Scheibe et al., 2005). For instance, plastidic photosystems are damaged by both intense light and/or low temperatures (i.e., chilling and freezing) (Jansen et al., 1999; Kudoh and Sonoike, 2002; Nishiyama et al., 2001), in which photon fluxes as low as $5 \mu \mathrm{mol} \cdot \mathrm{m}^{-2} \cdot \mathrm{s}^{-1} P P F$ can cause an increase in total loss of function to photosystem II (PSII), especially at levels below light saturation (Jansen et al., 1999). It is likely that the light levels used by Kozik and Wehner (2008), which were almost twice that used by Chung et al. (2003) and that reported here, resulted in substantial damage to PSII. Such damage likely affected the efficiency of PSII repair, which is directly dependent on the surrounding environmental conditions in which both high light and low temperature decrease efficiency of these repair operations (Govindachary et al., 2004, 2007; Kanervo et al., 2007).

Other photosystem-related responses have been detected in cucumber in response to chilling temperatures. Kudoh and Sonoike (2002) investigated photosystem I (PSI) damage in cucumber under conditions $\left(4{ }^{\circ} \mathrm{C}\right.$ for $5 \mathrm{~h}$, light levels at $190 \mu \mathrm{mol} \cdot \mathrm{m}^{-2} \cdot \mathrm{s}^{-1} \mathrm{PPF}$ ) similar to Chung et al. (2003) and that imposed here. They found that visible symptoms (e.g., tissue chlorosis) attributable to chilling were the consequence of photoinhibition of PSI. Specifically, PPF densities during chilling cause a chlorophyllic decrease, not $P P F$ applied in normal temperatures (Kudoh and Sonoike, 2002). 
Plastids are the first and most severely affected organelle in the plant cell when plants are challenged with chilling stress (Fowler and Limin, 2001). Therefore, plastidic responses might be more rapidly influenced by small changes in chilling temperatures than those conditioned by nuclear genes. This might be a plausible explanation for the germplasm chilling differences observed by Chung et al. (2003) and Kozik and Wehner (2008) and those reported here. For instance, the experimental chilling conditions imposed by Kozik and Wehner (2008) might cause a plastidic response that is beyond its maximum biochemical and/or mechanistic capacity to condition a tolerance response [threshold of internal damage (Scheibe et al., 2005)]. Moreover, if both the plastid and nucleus contribute to chilling response, then as one becomes inoperable, the other could provide a physiological mechanism for a tolerant response. Likewise, genotypic differences in plastid or nuclear constitution (e.g., one organelle tolerant and the other susceptible) could elicit similar responses under a given set of environmental conditions (i.e., $t /$ chch and $s / C h \_$).

The direct influence of the $C h$ gene on seedlings during chilling was examined here by evaluating $\mathrm{F}_{1}$ progeny derived from crossing the nuclear $C h$ donor, $\mathrm{NC}-76$, with $\mathrm{CBC}_{5}$ and $\mathrm{MBC}_{5}$, two lines whose chilling response is determined by their respective plastome genotypes. These $\mathrm{F}_{1} \mathrm{~s}$ were tested at the less severe conditions of Chung et al. (2003) than those of Kozik and Wehner (2008) to evaluate any potential augmentation of $C h$ on plastid-conferred chilling response. Although Kozik and Wehner (2008) defined NC-76 as possessing a dominant factor for chilling tolerance, it is only partially tolerant to chilling conditions in the heterozygous state $(C h / c h)$. Line NC-76 $(s / C h C h)$ was strategically crossed with $\mathrm{CBC}_{5}(t / c h c h)$ and $\mathrm{MBC}_{5}(\mathrm{~s} /$ chch $)$ to create $\mathrm{F}_{1}$ progeny possessing contrasting plastid types but similar (i.e., $\mathrm{Ch} / \mathrm{ch}$ ) nuclear genotypes. This allowed for the critical evaluation of chilling responses (i.e., tolerant versus susceptible) attributable solely to plastidic or nuclear sources. Placement of the tolerant $\mathrm{CH}$ plastid into a the susceptible nuclear background of M29 resulted in backcross progeny whose only tolerant contribution is found in the plastome because the genetic contributions of the mitochondria are inherited paternally in cucumber (Havey, 1997).

Based on findings of Kozik and Wehner (2008) and the data presented here (Tables 1 to 3; Figs. 1 and 2), it can be deduced that NC-76 possesses a chilling-tolerant nuclear factor and a susceptible plastid type $(s / C h C h)$. That is, all parental lines, hybrids $\left(\mathrm{F}_{1}\right)$, and backcross progeny possessing the tolerant plastid responded similarly to chilling challenge regardless of their nuclear constitution. In fact, under the chilling conditions described here, the average chilling response of NC-76 was intermediate between that of parental lines $\mathrm{CH}$ and M29. It is, therefore, hypothesized that the homozygous state of the nuclear tolerance gene $(C h)$ resident in $\mathrm{NC}-76$ augments a susceptible plastid type $(s)$ to provide a slightly more tolerant response than that observed in M29 (s/chch) under the chilling conditions used here. With similar logic, both $\mathrm{CBC}_{5} \times \mathrm{NC}-76$ and $\mathrm{MBC}_{5} \times \mathrm{NC}-76 \mathrm{~F}_{1}$ progeny would predictably be tolerant $[(t / C h c h)$ and/or $(s / C h c h)]$ to chilling temperatures if the dominant $C h$ allele contributed more significantly than the plastid. However, $\mathrm{F}_{1}$ progeny (heterozygous $\mathrm{Chch}$ ) differed in response and were influenced by plastid type and not nuclear content. Thus, it must be concluded that, under the environmental conditions set forth in this study, the maternal plastid contribution provided is more predictive than the nuclear contribution in determining the chilling phenotype of the cross-progeny examined here (Table 2; Fig. 2).

Identification of plastomic control of chilling response requires experimental conditions that would allow the plastid to remain operable during and after (recovery) the chilling episode. Given previous reports (Kudoh and Sonoike, 2002) and the results of this study, it is hypothesized that differences in genotypic response to chilling temperatures (i.e., between tolerant cucumber $\mathrm{CH}$ and susceptible cucumber genotypes (e.g., Gy14, M29) (Chung et al., 2003; Kozik and Wehner, 2008; Smeets and Wehner, 1997; this study) is the result of the presence/absence of a tolerant plastidic genotype ( $t$ versus $s$ ) or a plastidic incapacitation related to severe chilling conditions (i.e., intense light and extended low temperature exposure). This hypothesis could be tested by evaluating the chilling response of an advanced backcross progeny line (NC-76 recurrent parent) originating from an original $\mathrm{CH} \times \mathrm{NC}-76$ mating. Such cross-progeny would contain both plastidic $(\mathrm{CH}$, tolerant plastid) and homozygous dominant nuclear (NC-76, nuclear tolerant $\mathrm{Ch}$ ) chilling-tolerant components. Individuals with this genotype $(t / \mathrm{ChCh})$ would presumably be chillingtolerant under the experimental conditions described by Kozik and Wehner (2008) as well as those used by Chung et al. (2003) and Smeets and Wehner (1997).

The effect of $C h$ on chilling response was negligible in cross-progeny under the chilling conditions applied here. In contrast, plastid type was directly associated with chilling response in cross-progeny (Tables 1 to 3 ). For instance, the CI of $\mathrm{CH}$ and $\mathrm{M} 29$ differed from individuals with nearly identical nuclear constitutions $\left(\mathrm{MBC}_{5}\right.$ and $\mathrm{CBC}_{5}$, respectively) but with contrasting plastid type. Moreover, the re-introduction of the original plastid type by crossing $\mathrm{M} 29$ and $\mathrm{CBC}_{5}$ and $\mathrm{CH}$ with $\mathrm{MBC}_{5}$ restored the chilling response type observed in parental types (i.e., $\mathrm{CH}$ and M29). Thus, it may be concluded that a simple, yet effective, form of breeding CI tolerance into elite cultivars (e.g., backcrossing) may be effective for the introduction of plastomes conferring a CI-tolerant phenotype. Because cucumber plastomes are inherited maternally, introgression of such factors would be a relatively rapid process during plant improvement.

\section{Literature Cited}

Choi, D., E.M. Rodriguez, and T.J. Close. 2002. Barley Cbf3 gene identification, expression pattern, and map location. Plant Physiol. 129:1781-1787.

Chung, S., V.S. Gordon, and J.E. Staub. 2007. Sequencing cucumber (Cucumis sativus L.) chloroplast genomes identifies difference between chilling-tolerant and -susceptible cucumber lines. Genome 50:215-225.

Chung, S., J.E. Staub, and G. Fazio. 2003. Inheritance of chilling injury: A maternally inherited trait in cucumber. J. Amer. Soc. Hort. Sci. 128:526-530.

Foolad, M.R., J.R. Hyman, and G.Y. Lin. 1999. Relationships between cold- and salt-tolerance during seed germination in tomato: Analysis of response and correlated response to selection. Plant Breed. 118: $49-52$.

Fowler, D.B. and A.E. Limin. 2001. Impact of cold stress. 7 May 2009. $<$ http://www.plantstress.com/Articles/cold_i/cold_i.htm $>$.

Goldschmidt-Clermont, M. 1998. Coordination of nuclear and chloroplast gene expression in plant cells. Intl. Rev. Cytol. 177:115-180. Govindachary, S., C. Bigras, J. Harnois, D. Joly, and R. Carpentier. 2007. Changes in the mode of electron flow to photosystem I 
following chilling-induced photoinhibition in a $\mathrm{C}_{3}$ plant, Cucumis sativus L. Photosynth. Res. 94:333-345.

Govindachary, S., N.G. Bukhov, D. Joly, and R. Carpentier. 2004. Photosystem II inhibition by moderate light under low temperature in intact leaves of chilling-sensitive and -tolerant plants. Physiol. Plant. 121:322-333.

Gray, K.M. and E.P. Greenberg. 1992. Physical and functional maps of the luminescence gene cluster in an autoinducer-deficient Vibrio fischeri strain isolated from a squid light organ. J. Bacteriol. 174:4384-4390.

Havey, M.J. 1997. Predominant paternal transmission of the mitochondrial genome in cucumber. J. Hered. 88:232-235.

Iturriaga, G., M.A.F. Cushman, and J.C. Cushman. 2006. An EST catalogue from the resurrection plant Selaginella lepidophylla reveals abiotic stress-adaptive genes. Plant Sci. 170:1173-1184.

Jansen, M.A.K., A.K. Mattoo, and M. Edelman. 1999. D1-D2 protein degradation in the chloroplast. Eur. J. Biochem. 260:527-532.

Kanervo, E., M. Suorsa, and E. Aro. 2007. Assembly of protein complexes in plastids, p. 283-313. In: Bock, R. (ed.). Topics in current genetics.. Springer-Verlag, Heidelberg, Germany.

Kant, P., M. Gordon, S. Kant, G. Zolla, O. Davydov, and Y.M. Heimer. 2008. Functional-genomics-based identification of genes that regulate Arabidopsis responses to multiple abiotic stresses. Plant Cell Environ. 31:697-714.

Komori, T. and H. Imaseki. 2005. Transgenic rice hybrids that carry the $r f-1$ gene at multiple loci show improved fertility at low temperature. Plant Cell Environ. 28:425-431.

Kozik, E.U. and T.C. Wehner. 2008. A single dominant gene $C h$ for chilling resistance in cucumber seedlings. J. Amer. Soc. Hort. Sci. 133:225-227.

Kreps, J.A., Y. Wu, H.S. Chang, T. Zhu, X. Wang, and J.F. Harper. 2002. Transcriptome changes for Arabidopsis in response to salt, osmotic, and cold stress. Plant Physiol. 130:2129-2141.

Kudoh, H. and K. Sonoike. 2002. Irreversible damage to photosystem I by chilling in the light: Cause of the degradation of chlorophyll after returning to normal growth temperature. Planta 215:541-548.
Lynch, D.V. 1990. Chilling injury in plants: The relevance of membrane lipids, p. 17-34. In: Katterman, F. (ed.). Environmental injury to plants. Academic Press, New York, NY.

Mayfield, S.P. 1990. Chloroplast gene regulation: Interaction of the nuclear and chloroplast genomes in the expression of photosynthetic proteins. Curr. Opin. Cell Biol. 2:509-513.

Nishiyama, Y., H. Yamamoto, S. Allakhverdiev, M. Inaba, A. Yokota, and N. Murata. 2001. Oxidative stress inhibits the repair of photodamage to the photosynthetic machinery. EMBO J. 20:5587-5594.

Rodermel, S. 2001. Pathways of plastid-to-nucleus signaling. Trends Plant Sci. 6:471-478.

Sabehat, A., D. Weiss, and S. Lurie. 1998. Heat-shock proteins and cross-tolerance in plants. Physiol. Plant. 103:437-441.

Scheibe, R., J.E. Backhausen, V. Emmerlich, and S. Holtgrefe. 2005. Strategies to maintain redox homeostasis during photosynthesis under changing conditions. J. Expt. Bot. 56:1481-1489.

Smeets, L. and T. Wehner. 1997. Environmental effects on genetic variation of chilling resistance in cucumber. Euphytica 97: 217-225.

Staub, J.E. and J. Bacher. 1997. Cucumber as a processed vegetable. In: Processing vegetables: Science and technology IV. Technomic, Lancaster, PA.

Staub, J.E. and T.C. Wehner. 1996. Noninfectious disorders: Temperature stress, p. 66-87. In: Zitter, T.A., D.L. Hopkins, and C.E. Thomas (eds.). Compendium of cucurbit diseases Part II. APS Press, St. Paul, MN.

Susek, R.E. and J. Chory. 1992. A tale of two genomes: Role of a chloroplast signal in coordinating nuclear and plastid genome expression. Funct. Plant Biol. 19:387-399.

Takahashi, R., E.R. Benitez, H. Funatsuki, and S. Ohnishi. 2005. Soybean maturity and pubescence color genes improve chilling tolerance. Crop Sci. 45:1387-1393.

Wehner, T.C. 1982. Genetic variation for low-temperature germination ability in cucumber. Cucurbit Genet. Coop. Rpt. 5:16-17. 